\title{
High-Performance Cotton Fabric-Based Supercapacitors Consisting of Polypyrrole/Ag/Graphene Oxide Nanocomposite Prepared Via UV-Induced Polymerization
}

\section{Chunliu Liang}

Guilin University of Technology

Limin Zang ( zanglimin0705@163.com )

Guilin University of Technology

Fangfang Shi

Guilin University of Technology

Chao Yang

Guilin University of Technology

Jianhui Qiu

Akita Prefectural University

Qifan Liu

Akita Prefectural University

Zhenming Chen

Hezhou University

\section{Research Article}

Keywords: Polypyrrole, Silver nanoparticles, Cotton fabric, Flexible supercapacitor, UV-induced polymerization

Posted Date: October 27th, 2021

DOI: https://doi.org/10.21203/rs.3.rs-1009537/v1

License: (9) This work is licensed under a Creative Commons Attribution 4.0 International License. Read Full License

Version of Record: A version of this preprint was published at Cellulose on February 3rd, 2022. See the published version at https://doi.org/10.1007/s10570-022-04454-4. 


\section{Abstract}

Cotton fabric (CF) fabricated by natural cellulose fibers has porous structure and abundant hydrophilic hydroxyl groups, which is a promising substrate for flexible fabric-based supercapacitors. Graphene oxide (GO) nanosheets were fixed on the CF by vacuum filtration, and then the pyrrole monomers and silver ions $\left(\mathrm{Ag}^{+}\right)$were adsorbed to the surface of $\mathrm{GO} / \mathrm{CF}$ by $\pi-\pi$ and electrostatic interactions, respectively. Polypyrrole/silver (PPy/Ag) nanoparticles were in situ generated on the surface of GO/CF via UV-induced polymerization, forming the flexible $\mathrm{PPy} / \mathrm{Ag} / \mathrm{GO} / \mathrm{CF}$ electrodes. The electrodes combine three active materials (PPy, Ag and GO) show good electrochemical performance. The electrode prepared under optimum conditions (UV irradiation time: 120 min; mass loading of GO on the CF: $3 \mathrm{mg} \mathrm{cm}^{-2}$ ) exhibits a high specific capacitance of $1664.0 \mathrm{mF} \mathrm{cm}{ }^{-2}$ ). The flexible symmetric quasi-solid-state fabric-based supercapacitor (QFSC) based on the optimum electrode also keeps superior electrochemical performance and excellent mechanical flexibility, which is expected to have great application prospect for wearable energy storage devices.

\section{Introduction}

With the rapid development of wearable technology, various wearable electronic products emerge in an endless stream, which in turn makes flexible energy storage devices become a research hotspot (Dubal et al. 2018; Sumboja et al. 2018; Yu et al. 2019). Among several popular flexible energy storage devices (flexible supercapacitors, flexible lithium-ion batteries, flexible zinc-ion batteries, etc.), flexible supercapacitors are particularly noticeable due to their environmental friendliness, fast charge/discharge rate, high power density, long cycle life and superior mechanical flexibility (Jia et al. 2020; Keum et al. 2020; Zhang et al. 2021). Especially, flexible fabric-based supercapacitors are regarded as the suitable energy storage device for wearable electronic devices because they are easy to integrate into cloths. In addition, the 3D porous structure and excellent mechanical flexibility of the fabrics are conducive to loading more active materials on the fabrics and improving the electrochemical and mechanical performance of the fabric-based supercapacitors (Barakzehi et al. 2019; Li et al. 2021; Liu et al. 2020a). Compared with the synthetic fabrics consisting of man-made fibers, cotton fabric (CF) fabricated by natural cellulose fibers has good hydrophilicity, breathability and renewability, which is a promising candidate for flexible fabric-based supercapacitors (Li et al. 2019; Lv et al. 2019a; Wang et al. 2021; Zhang et al. 2019).

To fabricate flexible supercapacitors, graphene is often applied as the active material on account of its large specific surface area, good electrical conductivity, high mechanical robustness and outstanding cycling stability (Huang et al. 2018; Purkait et al. 2018; Wu and Shao 2021). However, the poor hydrophilicity, strong van der Waals forces and $\pi-\pi$ interactions of graphene can have negative effects on its electrochemical performance. After oxidation, the obtained graphene oxide (GO) shows improved hydrophilicity and the abundant oxygen-containing functional groups of GO can have strong interaction with the hydroxyl groups of $\mathrm{CF}$, which are advantageous to obtaining the flexible fabric-based supercapacitor with good electrochemical and mechanical performance by loading GO on the CF 
(GO/CF). Even so, limited by the electric double layer capacitance (EDLC) mechanism of GO, the specific capacitance of $\mathrm{GO} / \mathrm{CF}$ needs to be further improved by introduction of other active materials.

Polypyrrole (PPy), as a representative conducting polymer, is one of the most concerned pseudocapacitive materials for flexible supercapacitors in light of its good environmental stability, outstanding electrochemical properties, easy preparation, high conductivity and low cost (Kim and Shin 2021; Liu et al. 2019; Wang et al. 2020a; Zang et al. 2020). The composite electrodes containing pseudocapacitive PPy and electric double layer capacitive GO possess improved electrochemical performance due to the synergistic effect (Wang et al. 2018a; Wang et al. 2020b; Wang et al. 2018b; Zhang et al. 2017). To obtain PPy, UV-induced polymerization of pyrrole in the presence of silver ions $\left(\mathrm{Ag}^{+}\right)$has been proven to be a simple and effective method (Liang et al. 2021; Zang et al. 2016). This strategy can not only obtain PPy nanoparticles in a relatively short time, but also generate $\mathrm{Ag}$ nanoparticles simultaneously. The incorporation of Ag nanoparticles can improve the electrical conductivity and store energy via reversible redox reaction (Li et al. 2018; Liang et al. 2021), which can further enhance the electrochemical performance of the electrode materials.

Thus, in this study, GO nanosheets were anchored on the CF by vacuum filtration to obtain the flexible GO/CF firstly, and then PPy/Ag nanoparticles were in situ formed on the GO/CF to achieve the flexible $\mathrm{PPy} / \mathrm{Ag} / \mathrm{GO} / \mathrm{CF}$ electrodes via UV-induced polymerization. The strong interactions among components and high mechanical flexibility of the CF endow the PPy/Ag/GO/CF electrodes with outstanding mechanical flexibility and robustness. Moreover, the PPy/Ag/GO/CF electrodes show superior electrochemical performance owing to the combination of PPy, Ag and GO. The effects of UV irradiation time as well as the mass loading of GO on the CF on the electrochemical properties were studied. The $\mathrm{PPy} / \mathrm{Ag} / \mathrm{GO} / \mathrm{CF}$ electrode with the best electrochemical performance was further used to fabricate a flexible symmetric supercapacitor which also exhibits excellent mechanical flexibility and electrochemical performance.

\section{Experimental Section \\ 2.1 Materials}

Graphite, sulfuric acid $\left(\mathrm{H}_{2} \mathrm{SO}_{4}, 98 \%\right)$, nitric acid $\left(\mathrm{HNO}_{3}, 68 \%\right)$, potassium permanganate $\left(\mathrm{KMnO}_{4}\right)$, sodium nitrate $\left(\mathrm{NaNO}_{3}\right)$, hydrogen peroxide $\left(\mathrm{H}_{2} \mathrm{O}_{2}, 30 \%\right)$, ethanol, pyrrole, silver nitrate $\left(\mathrm{AgNO}_{3}\right)$, ammonium persulfate (APS) and poly(vinyl alcohol) (PVA) were analytically pure and bought from Aladdin Co. Ltd.

\subsection{Fabrication of graphene oxide/cotton fabric (GO/CF)}

CF $\left(5 \times 5 \mathrm{~cm}^{2}\right)$ was cut from old T-shirts and washed with ethanol to remove impurities before use. GO was synthesized according to the modified Hummers method (Tian et al. 2019), and then was dispersed in distilled water to obtain a $\mathrm{GO}$ suspension $\left(2 \mathrm{mg} \mathrm{mL}^{-1}\right)$. GO/CF was prepared by vacuum filtration and then dried at $80^{\circ} \mathrm{C}$ for $12 \mathrm{~h}$. The as-prepared GO/CF with 1, 2, 3 and $4 \mathrm{mg}$ of $\mathrm{GO}$ on one square centimeter of $\mathrm{CF}$ are labeled as $1 \mathrm{GO} / \mathrm{CF}, 2 \mathrm{GO} / \mathrm{CF}, 3 \mathrm{GO} / \mathrm{CF}$ and $4 \mathrm{GO} / \mathrm{CF}$, respectively. 


\subsection{Fabrication of flexible PPy/Ag/GO/CF electrodes}

The PPy/Ag/GO/CF electrodes were prepared by UV-induced polymerization. Typically, $0.25 \mathrm{~mL}$ of pyrrole was stirred in $25 \mathrm{~mL}$ of distilled water for $30 \mathrm{~min}$ in an ice-water bath, and then $10 \mathrm{~mL}$ of $\mathrm{AgNO}_{3}$ solution (containing $0.612 \mathrm{~g}$ of $\mathrm{AgNO}_{3}$ ) was added with stirring for $5 \mathrm{~min}$. Then the mixture and GO/CF were transferred to a petri dish to perform the UV-induced polymerization (wavelength of the UV light: $365 \mathrm{~nm}$ ). After UV irradiation for a certain time, the samples were washed with distilled water and ethanol, and dried at $40^{\circ} \mathrm{C}$ in a vacuum for $12 \mathrm{~h}$ to obtain the PPy/Ag/GO/CF electrodes. The final PPy/Ag/GO/CF

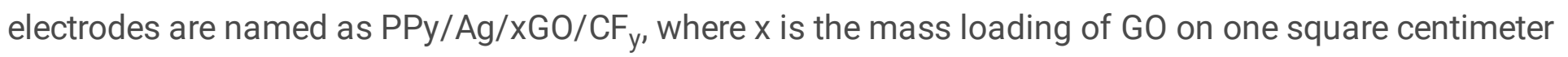
of $\mathrm{CF}\left(1,2,3\right.$ and $\left.4 \mathrm{mg} \mathrm{cm}^{-2}\right)$ and y means the UV irradiation time $(60,90,120$ and $150 \mathrm{~min})$.

For comparison, traditional chemical polymerization of pyrrole was also performed to prepare the fabricbased electrode. In brief, $0.25 \mathrm{~mL}$ of pyrrole and $0.33 \mathrm{~g}$ of $\mathrm{HNO}_{3}$ were stirred in $25 \mathrm{~mL}$ of distilled water for $30 \mathrm{~min}$ in an ice-water bath, and then $3 \mathrm{GO} / \mathrm{CF}$ was added into the mixture. Afterwards, $10 \mathrm{~mL}$ of APS solution (containing $0.83 \mathrm{~g}$ of APS) was slowly added into the mixture within $20 \mathrm{~min}$, and the mixture was stirred for $8 \mathrm{~h}$ in an ice-water bath to obtain the PPy/3GO/CF electrode.

\subsection{Assembly of flexible quasi-solid-state fabric-based supercapacitor (QFSC)}

Firstly, PVA/ $\mathrm{H}_{2} \mathrm{SO}_{4}$ gel electrolyte was prepared by dissolving $6 \mathrm{~g}$ of PVA in $60 \mathrm{~mL}$ of $1 \mathrm{M} \mathrm{H}_{2} \mathrm{SO}_{4}$ solution at $85^{\circ} \mathrm{C}$ and then cooled to room temperature. Two pieces of $\mathrm{PPy} / \mathrm{Ag}_{3} \mathrm{GO} / \mathrm{CF}_{120}$ electrodes were immersed in the PVA/ $\mathrm{H}_{2} \mathrm{SO}_{4}$ electrolyte for $5 \mathrm{~min}$ and dried for $60 \mathrm{~min}$ at room temperature. The QFSC with a sandwich structure was assembled by pressing the above electrodes together (effective area: $1 \times 1$ $\left.\mathrm{cm}^{2}\right)$.

\subsection{Characterization}

The morphology and structure of the samples were characterized by field emission scanning electron microscope (SEM, ZEISS Sigma 300), Raman spectroscopy (Thermo Scientific DXR), X-ray diffractometer (XRD, PANalytical X' Pert Pro) and X-ray photoelectron spectroscopy (XPS, Thermo Scientific ESCALAB 250Xi). The electrochemical properties of the electrodes and QFSC were tested by $\mathrm{CS} 2350 \mathrm{H}$ electrochemical workstation (Wuhan Corrtest Instruments Co. Ltd.). The electrochemical calculations are given in the Supporting Information.

\section{Results And Discussion}

Figure 1 schematically illustrates the fabrication process of the flexible PPy/Ag/GO/CF electrodes by UVinduced polymerization. The CF obtained from old T-shirts is woven by natural cellulose fibers, which has hydroxyl groups and porous microstructure (Fig. S1a). After vacuum filtration of GO suspension, GO nanosheets are coated on the CF (Fig. S1b) and has strong interactions with CF owing to the hydrogen bonds formed between oxygen-containing functional groups of GO and hydroxyl groups of CF. As 
confirmed in Fig. S2, no GO nanosheets fall off the CF even after ultrasonic treatment for 120 min. When $\mathrm{GO} / \mathrm{CF}$ is submerged in the aqueous solution containing pyrrole and $\mathrm{AgNO}_{3}$, the pyrrole monomers are gathered on the surface of $\mathrm{GO} / \mathrm{CF}$ due to $\pi-\pi$ interaction between pyrrole and $\mathrm{GO}$. Meanwhile $\mathrm{Ag}^{+}$ions are also adsorbed onto the surface of GO/CF due to electrostatic interaction between $\mathrm{Ag}^{+}$and $\mathrm{GO}$. The formation mechanism of PPy/Ag composite by UV-induced polymerization is shown in Fig. S3 (Zang et al. 2016). Pyrrole monomers are excited and undergo polymerization to form PPy when exposure to UV light, and $\mathrm{Ag}^{+}$ions are reduced to the metallic Ag nanoparticles at the same time, leading to the formation of flexible PPy/Ag/GO/CF electrodes.

Raman spectra of $3 \mathrm{GO} / \mathrm{CF}$ and $\mathrm{PPy} / \mathrm{Ag} / 3 \mathrm{GO} / \mathrm{CF}_{120}$ are displayed in Fig. 2a. For 3GO/CF, two marked peaks at $1346 \mathrm{~cm}^{-1}$ ( $\mathrm{D}$ band) attributed to the defects and/or edges of carbon atom lattice and 1592 $\mathrm{cm}^{-1}$ (G band) assigned to in-plane stretching vibration of $\mathrm{sp}^{2}$ hybridized carbon appear (Han et al. 2018). For $\mathrm{PPy} / \mathrm{Ag} / 3 \mathrm{GO} / \mathrm{CF}_{120}$, the main peaks of PPy are confirmed, including ring in-plane deformation associated with radical cation at $974 \mathrm{~cm}^{-1}$, symmetrical $\mathrm{C}-\mathrm{H}$ in-plane bending at $1041 \mathrm{~cm}^{-1}, \mathrm{C}-\mathrm{C}$ in-ring stretching at $1340 \mathrm{~cm}^{-1}$ and $\mathrm{C}=\mathrm{C}$ stretching of the PPy backbone at $1581 \mathrm{~cm}^{-1}$ (Lv et al. 2019b; Zuo et al. 2020). Additionally, D band and $G$ band of $G O$ are shifted and overlapped with the peaks of PPy, which is resulted from $\pi-\pi$ interaction between PPy and GO (Singu and Yoon 2018). Fig. 2b shows the XRD patterns of $3 \mathrm{GO} / \mathrm{CF}$ and $\mathrm{PPy} / \mathrm{Ag} / 3 \mathrm{GO} / \mathrm{CF}_{120}$. The strong diffraction peak of $3 \mathrm{GO} / \mathrm{CF}$ at $2 \theta=10.6^{\circ}$ is ascribed to the (001) diffraction of GO. The interlayer distance between graphene layers of the $\mathrm{GO}$ is 0.86 $\mathrm{nm}$ according to the Bragg's equation, which is wider than that of the corresponding graphite due to the presence of oxygen-containing functional groups (Fan et al. 2017; Saleem et al. 2018). For the XRD pattern of $\mathrm{PPy} / \mathrm{Ag} / 3 \mathrm{GO} / \mathrm{CF}_{120}$, five peaks loaded at $38.0^{\circ}, 44.2^{\circ}, 64.3^{\circ}, 77.3^{\circ}$ and $81.5^{\circ}$ are corresponded to the (111), (200), (220), (311) and (222) planes of Ag with face-centered cubic structure (JCPDS 870597) (Cai et al. 2017). It is indicated that $\mathrm{Ag}^{+}$ions have been reduced to metallic Ag nanoparticles during UV-induced polymerization process. Moreover, the diffraction peak of $\mathrm{GO}$ decreases because the $3 \mathrm{GO} / \mathrm{CF}$ is covered by PPy/Ag nanoparticles.

To further confirm the chemical state of the PPy/Ag/GO/CF electrodes, $3 \mathrm{GO} / \mathrm{CF}$ and $\mathrm{PPy} / \mathrm{Ag} / 3 \mathrm{GO} / \mathrm{CF}_{120}$ are analyzed by XPS spectra. As shown in Fig. 3a, the XPS survey spectrum of 3GO/CF has two prominent peaks referring $\mathrm{C} 1 \mathrm{~s}$ and $01 \mathrm{~s}$, and $\mathrm{PPy} / \mathrm{Ag} / 3 \mathrm{GO} / \mathrm{CF}_{120}$ shows four major peaks referring to $\mathrm{C} 1 \mathrm{~s}$, 01s, N1s and Ag3d, indicating the formation of PPy and Ag via UV-induced polymerization. Fig. 3b reveals the high-resolution XPS spectrum of $\mathrm{C} 1 \mathrm{~s}$ in the $\mathrm{PPy} / \mathrm{Ag} / 3 \mathrm{GO} / \mathrm{CF}_{120}$, in which the prominent peaks of $\mathrm{C}-\mathrm{C}(284.0 \mathrm{eV}), \mathrm{C}-\mathrm{N}(285.3 \mathrm{eV}),=\mathrm{C}-\mathrm{NH}^{+}(286.6 \mathrm{eV})$ and $-\mathrm{C}=\mathrm{N}^{+}(288.4 \mathrm{eV})$ can be distinguished (Singu and Yoon 2018). More significantly, the high-resolution XPS spectrum of N1s shown in Fig. 3c can be divided into four peaks, including $-\mathrm{N}=(397.2 \mathrm{eV}),-\mathrm{NH}-(399.2 \mathrm{eV}),-\mathrm{N}^{+}-(400.8 \mathrm{eV})$ and $\mathrm{NO}_{3}{ }^{-}(405.7 \mathrm{eV})$ (Cao et al. 2015). The existence of protonated benzenoid amine nitrogen demonstrates that the PPy has been doped. The high-resolution XPS spectrum of Ag3d shown in Fig. $3 d$ has two peaks of $\mathrm{Ag}^{3} \mathrm{~d}_{5 / 2}$ $(367.7 \mathrm{eV})$ and $\mathrm{Ag3d}_{3 / 2}(373.7 \mathrm{eV})$, proving the presence of Ag nanoparticles (Zhou et al. 2020). 
The effects of UV irradiation time on the morphology and electrochemical properties of the electrodes are studied. Fig. 4 shows the SEM images of PPy/Ag/1GO/CF electrodes with different UV irradiation time. $\mathrm{PPy} / \mathrm{Ag} / 1 \mathrm{GO} / \mathrm{CF}_{60}$ possesses plenty of holes because the PPy/Ag nanoparticles generated within 60 min are limited and cannot completely cover the surface of GO/CF. With the UV irradiation time extends, the generated PPy/Ag nanoparticles become more and more, and the surface morphology of $\mathrm{PPy} / \mathrm{Ag} / 1 \mathrm{GO} / \mathrm{CF}_{\mathrm{y}}$ electrode gets denser and denser. Specifically, the produced PPy/Ag nanoparticles on the $1 \mathrm{GO} / \mathrm{CF}$ in $60,90,120$ and $150 \mathrm{~min}$ are $0.9,2.9,3.5$ and $3.9 \mathrm{mg} \mathrm{cm}^{-2}$, respectively. The electrochemical properties of $\mathrm{PPy} / \mathrm{Ag} / 1 \mathrm{GO} / \mathrm{CF}_{\mathrm{y}}$ electrodes are investigated by cyclic voltammetry $(\mathrm{CV})$, galvanostatic charge/discharge (GCD) and electrochemical impedance spectroscopy (EIS). As shown in Fig. 5a, the CV curves of PPy/Ag/1GO/CFy electrodes have a pair of redox peaks situated in $\sim 0.56 \mathrm{~V}$ and $\sim 0.48 \mathrm{~V}$, which are associated with faradic reactions of $\mathrm{Ag} / \mathrm{Ag}^{+}$( $\mathrm{Li}$ et al. 2018; Wei et al. 2013). GCD curves of $\mathrm{PPy} / \mathrm{Ag} / 1 \mathrm{GO} / \mathrm{CF}_{\mathrm{y}}$ electrodes (Fig. $5 \mathrm{~b}$ ) exhibit voltage platforms, which correspond to the $\mathrm{CV}$ curves. The PPy/Ag/1GO/CF 120 electrode exhibits the largest $\mathrm{CV}$ curve area and longest discharge time, suggesting it has the highest specific capacitance. By calculation, the areal specific capacitance $\left(C_{A}\right.$, electrode $)$ and volumetric specific capacitance $\left(C_{V}\right.$, electrode $)$ of the PPy $/ \mathrm{Ag} / 1 \mathrm{GO} / \mathrm{CF}_{\mathrm{y}}$ electrodes at different current densities are shown in Fig. S4. Among them, the PPy/Ag/1GO/CF 120 electrode has the highest $C_{A}$, electrode of $690.3 \mathrm{mF} \mathrm{cm}^{-2}$ and $C_{V \text {, electrode }}$ of $11.4 \mathrm{~F} \mathrm{~cm}^{-3}$ at a current density of $0.5 \mathrm{~mA} \mathrm{~cm}^{-2}$. When the current density increases to $5 \mathrm{~mA} \mathrm{~cm}{ }^{-2}$, the PPy/Ag/1GO/CF 120 electrode still shows the highest $C_{A}$, electrode of $237.9 \mathrm{mF} \mathrm{cm}{ }^{-2}$ and $C_{V \text {, electrode }}$ of $3.9 \mathrm{~cm}^{-3}$. The result demonstrates that $120 \mathrm{~min}$ is the optimum UV irradiation time for preparation of $\mathrm{PPy} / \mathrm{Ag} / \mathrm{GO} / \mathrm{CF}$ electrode with high specific capacitance. Although the produced PPy/Ag nanoparticles in $150 \mathrm{~min}$ is more than that in $120 \mathrm{~min}$, the dense and compact structure of $\mathrm{PPy} / \mathrm{Ag} / 1 \mathrm{GO} / \mathrm{CF}_{150}$ will cause that less active sites can be exposed and the diffusion of electrolyte ions becomes more difficult. Nyquist plots of the PPy/Ag/ $1 \mathrm{GO} / \mathrm{CF}_{\mathrm{y}}$ electrodes shown in Fig. $5 \mathrm{c}$ are divided into two regions, including the semicircle at the high-frequency region and the straight line at the low-frequency region. The PPy/Ag/1GO/CF ${ }_{120}$ electrode possesses the lowest charge transfer resistance $\left(R_{c t}\right)$ of $12.4 \Omega$, indicating that it has easy charge transfer at the electrode/electrolyte interface.

With more profound research, it is found that the mass loading of GO on the CF significantly affects the morphology and electrochemical properties of the electrodes. Fig. 6 shows the SEM images of $\mathrm{PPy} / \mathrm{Ag} / \mathrm{xGO} / \mathrm{CF}_{120}$ electrodes with different mass loading of $\mathrm{GO}$ on the CF. The produced PPy/Ag nanoparticles gradually increase and then decrease as the mass loading of $\mathrm{GO}$ on the $\mathrm{CF}$ increases. The produced PPy/Ag nanoparticles in PPy/ $\mathrm{Ag} / 3 \mathrm{GO} / \mathrm{CF}_{120}$ reach the maximum value of $6.3 \mathrm{mg} \mathrm{cm}^{-2}$, and the Ag, C, N and $\mathrm{O}$ elements are uniformly distributed (Fig. 6e-h). However, when the mass loading of GO on the $\mathrm{CF}$ is $4 \mathrm{mg} \mathrm{cm}^{-2}$, the surface of $\mathrm{PPy} / \mathrm{Ag} / 4 \mathrm{GO} / \mathrm{CF}_{120}$ shows various degrees of cracks. The $\mathrm{GO}$ has abundant oxygen-containing functional groups on its surface. The higher mass loading of GO on the CF means that more active sites are exposed, so more $\mathrm{Ag}^{+}$ions and pyrrole monomers are adsorbed on the surface of GO/CF to realize the high yield of PPy/Ag nanoparticles. But when the mass loading of GO on 
the $\mathrm{CF}$ is superabundant ( $4 \mathrm{mg} \mathrm{cm}^{-2}$ in this work), agglomeration happens due to the strong interactions between $\mathrm{GO}$ nanosheets, which leads to the appearance of cracks and the reduction of active sites. As a result, the produced PPy/Ag nanoparticles in $\mathrm{PPy} / \mathrm{Ag} / 4 \mathrm{GO} / \mathrm{CF}_{120}\left(5.1 \mathrm{mg} \mathrm{cm}^{-2}\right)$ is lower than that of $\mathrm{PPy} / \mathrm{Ag} / 3 \mathrm{GO} / \mathrm{CF}_{120}$.

The electrochemical properties of $\mathrm{PPy} / \mathrm{Ag} / 1 \mathrm{GO} / \mathrm{CF}_{120}, \mathrm{PPy} / \mathrm{Ag} / 2 \mathrm{GO} / \mathrm{CF}_{120}, \mathrm{PPy} / \mathrm{Ag} / 3 \mathrm{GO} / \mathrm{CF}_{120}$ and $\mathrm{PPy} / \mathrm{Ag} / 4 \mathrm{GO} / \mathrm{CF}_{120}$ electrodes are shown in Fig. 7. The PPy/Ag/3GO/CF 120 electrode exhibits the maximum value of $\mathrm{CV}$ curve area (Fig. 7a) and discharge time (Fig. $7 \mathrm{~b}$ ), indicating it has the best specific capacitance. As shown in Fig. S5, the $C_{A \text {, electrode }}$ of $\mathrm{PPy} / \mathrm{Ag} / 3 \mathrm{GO} / \mathrm{CF}_{120}$ electrode at a current density of $0.5 \mathrm{~mA} \mathrm{~cm}^{-2}$ is $1664.0 \mathrm{mF} \mathrm{cm}^{-2}\left(C_{V}\right.$, electrode $\left.27.0 \mathrm{~F} \mathrm{~cm}^{-3}\right)$ and reaches $780.7 \mathrm{mF} \mathrm{cm}^{-2}$ when the current density is $5 \mathrm{~mA} \mathrm{~cm}^{-2}\left(C_{V \text {, electrode }}: 12.7 \mathrm{~F} \mathrm{~cm}^{-3}\right)$. The high specific capacitance and good rate performance of $\mathrm{PPy} / \mathrm{Ag} / 3 \mathrm{GO} / \mathrm{CF}_{120}$ electrode is attributed to the highest content of $\mathrm{PPy} / \mathrm{Ag}$ nanoparticles. In addition, the PPy/Ag/3GO/CF 120 electrode has the smallest equivalent series resistance $\left(R_{\mathrm{S}}, 3.7 \Omega\right)$ and $\mathrm{R}_{\mathrm{ct}}(1.9 \Omega)$ according to the Nyquist plots shown in Fig. 7c, which is also conducive to the electrochemical performance. The $\mathrm{CV}$ curves of $1 \mathrm{GO} / \mathrm{CF}, 2 \mathrm{GO} / \mathrm{CF}, 3 \mathrm{GO} / \mathrm{CF}$ and $4 \mathrm{GO} / \mathrm{CF}$ shown in Fig. S6a present nearly rectangle shapes and the corresponding GCD curves shown in Fig. S6b display nearly symmetrical triangles, demonstrating the EDLC behavior of GO (Yang et al. 2020). Compared with PPy/Ag/GO/CF electrodes, the specific capacitance of GO/CF is very limited. The maximum $C_{A \text {, electrode }}$ of $\mathrm{GO} / \mathrm{CF}$ is only $14.4 \mathrm{~F} \mathrm{~cm}^{-2}$ a current density of $0.5 \mathrm{~mA} \mathrm{~cm}{ }^{-2}$, which indicates that the PPy/Ag nanoparticles have major contribution to the capacitance. To better illustrate the effect of Ag nanoparticles, the electrochemical properties of $\mathrm{PPy} / 3 \mathrm{GO} / \mathrm{CF}$ electrode and $\mathrm{PPy} / \mathrm{Ag} / 3 \mathrm{GO} / \mathrm{CF}_{120}$ electrode are compared in Fig. S7. The CV curve of the PPy/3GO/CF electrode is an approximately rectangular shape (Fig. S7a) and the GCD curve is approximately symmetrical triangle (Fig. S7b), revealing its typical capacitive behavior (Zang et al. 2020). Significantly different from the PPy/3GO/CF electrode, the CV curve of $\mathrm{PPy} / \mathrm{Ag} / 3 \mathrm{GO} / \mathrm{CF}_{120}$ electrode shows much larger enclosed area and the corresponding GCD curve has much longer discharge time than those of the PPy/3GO/CF electrode. The values of $C_{A \text {, electrode }}$ and $C_{V \text {, electrode }}$ of the $\mathrm{PPy} / 3 \mathrm{GO} / \mathrm{CF}$ electrode are only $393.7 \mathrm{mF} \mathrm{cm}^{-2}$ and $6.5 \mathrm{~F} \mathrm{~cm}^{-3}$ at a current density of $0.5 \mathrm{~mA} \mathrm{~cm} \mathrm{~cm}^{-2}$, respectively (Fig. S7c). The pair of strong peaks in the CV curve and the voltage platforms in the GCD curve are attributed to the reversible $\mathrm{Ag} / \mathrm{Ag}^{+}$redox, which indicate that the $\mathrm{Ag}$ nanoparticles can store/release charges and contribute to the capacitance (Li et al. 2018; Wei et al. 2013). Moreover, the presence of Ag nanoparticles in the electrode can increase the electrical conductivity and improve the charge transfer ability. According to the Nyquist plots shown in Fig. $S 7 d$, the $R_{S}$ and $R_{c t}$ of the PPy/3GO/CF electrode are $8.2 \Omega$ and $20.2 \Omega$, respectively, which are higher than those of the $\mathrm{PPy} / \mathrm{Ag} / 3 \mathrm{GO} / \mathrm{CF}_{120}$ electrode.

To sum up, there are four reasons can be explained the excellent electrochemical performance of the $\mathrm{PPy} / \mathrm{Ag} / 3 \mathrm{GO} / \mathrm{CF}_{120}$ electrode. $(\mathbb{\nabla})$ The $3 \mathrm{GO} / \mathrm{CF}$ can provide more active sites to effectively adsorb more pyrrole monomers and $\mathrm{Ag}^{+}$ions on its surface to form more PPy/Ag nanoparticles. (『) To perform the UVinduced polymerization for 120 min can achieve the high yield of PPy/Ag nanoparticles with appropriate 
compactness, which is beneficial to expose more active sites and achieve fast ion diffusion. (『) The Ag nanoparticles not only can effectively increase the electrical conductivity and improve the charge transfer ability of the electrode, but also can contribute to the capacitance through the reversible $\mathrm{Ag} / \mathrm{Ag}^{+}$redox. ( () The synergistic effect of the three active materials (PPy, Ag and GO) is advantageous to improve the electrochemical performance of the electrode. Two pieces of $\mathrm{PPy} / \mathrm{Ag} / 3 \mathrm{GO} / \mathrm{CF}_{120}$ electrode are further used to prepare the flexible QFSC (Fig. 8a). The CV curves of the QFSC show a pair of redox peaks at low scan rates, and the peaks gradually shift and become weak and wide with the increase of scan rate (Fig. $8 b)$. To better understand the charge storage mechanism of the QFSC, the relationship between the total measured voltammetry charge $\left(q_{v}\right)$ and inverse of the square root of the scan rate $\left(v^{-1 / 2}\right)$ is plotted in Fig. 8c. According to the electrochemical calculations given in the Supporting Information (Ardizzone et al. 1990), the outer surface charges $\left(q_{o}\right)$ of the QFSC which is a non-diffusion controlled process, is calculated to be $\sim 0.054 \mathrm{C} \mathrm{cm}^{-2}$ by linear fitting. The $q_{V}$ of the QFSC at $1,2,4,5,10$ and $20 \mathrm{mV} \mathrm{s}^{-1}$ are $0.19,0.16,0.14,0.13,0.10$ and $0.07 \mathrm{C} \mathrm{cm}^{-2}$, respectively. The corresponding ratios of non-diffusion contribution at different scan rates are shown in Fig. $8 \mathrm{~d}$. which increases from $28.5 \%$ at $1 \mathrm{mV} \mathrm{s}^{-1}$ to $77.9 \%$ at $20 \mathrm{mV} \mathrm{s}^{-1}$ because the electrolyte ions don't have enough time to diffuse into and diffuse out of the inner part of the active materials at high scan rates. The GCD curves with good symmetry demonstrate that the QFSC has superior electrochemical reversibility and high Coulombic efficiency (Fig. $8 \mathrm{e})$. Fig. S8 shows the areal specific capacitance $\left(C_{A \text {, device }}\right)$ and volumetric specific capacitance $\left(C_{V}\right.$, device) of the QFSC at $0.5,1,2,4$ and $5 \mathrm{~mA} \mathrm{~cm}^{-2}$, which reveals its high specific capacitance and excellent rate performance. The maximum $C_{A \text {, device }}$ and $C_{V \text {, device }}$ can reach $286.6 \mathrm{mF} \mathrm{cm}^{-2}$ and $4.7 \mathrm{~F} \mathrm{~cm}^{-3}$ at 0.5 $\mathrm{mA} \mathrm{cm}{ }^{-2}$, respectively. And the values of $R_{s}$ and $R_{c t}$ obtained from the Nyquist plot in Fig. $8 f$ are $5.3 \Omega$ and $2.4 \Omega$, respectively.

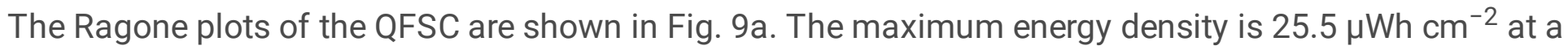
power density of $101.6 \mu \mathrm{W} \mathrm{cm}{ }^{-2}$, and the maximum power density is $1149.5 \mu \mathrm{W} \mathrm{cm}^{-2}$ at an energy density of $16.6 \mu \mathrm{Wh} \mathrm{cm}{ }^{-2}$. It is superior compared with other reported similar flexible supercapacitors, such as rGO/PPy (Barakzehi et al. 2019), Graphene/nanotube/PANI (Liu et al. 2020b), rGO/1, 4, 5, 8 tetrahydroxy anthraquinone (Xu et al. 2017), PPy CNT/cotton yarn plywood (Hao et al. 2021), PPy-PVA hydrogel (Zang et al. 2017), and graphene film (Li et al. 2017). Also, the capacitance retention of the QFSC is $90.5 \%$ after 10000 GCD cycles (Fig. 9b), demonstrating its good cycling stability. In addition, the QFSC exhibits outstanding flexibility. As shown in Fig. 9c, the CV curves are negligibly changed at different bending curvatures of $60^{\circ}, 120^{\circ}$ and $180^{\circ}$ compared with its normal state. Surprisingly, after 10000 bending cycles at a bending angle of $180^{\circ}$, the capacitance retention is still as high as $89.7 \%$, which is ascribed to that the $3 \mathrm{GO} / \mathrm{CF}$ can provide robust and flexible support for PPy/Ag nanoparticles to maintain the electrode integrity. At the same time, the working voltage and capacitance can be adjusted by connecting multiple QFSCs in series and in parallel to meet the practical requirements. Fig. 9e shows the GCD curves of multiple QFSCs connected in series and in parallel. The voltage window can extend to $2.4 \mathrm{~V}$ by connecting three QFSCs in series, and the discharge time increases three-folds while the working voltage is unchanged by connecting three QFSCs in parallel. For example, as shown in Fig. 9f, three 
QFSCs connected in series can power the electronic clock effortlessly, indicating the as-prepared QFSC is a good candidate for wearable electronics.

\section{Conclusion}

In summary, the flexible PPy/Ag/GO/CF electrodes can be conveniently obtained by efficient in situ UVinduced polymerization on the surface of GO/CF. The incorporation of Ag nanoparticles can effectively enhance the electrical conductivity and contribute to the capacitance through the reversible $\mathrm{Ag} / \mathrm{Ag}^{+}$redox. The optimum UV irradiation time and the mass loading of GO on the CF are determined to be 120 min and $3 \mathrm{mg} \mathrm{cm}^{-2}$, respectively. The corresponding PPy/Ag/3GO/CF 120 electrode exhibits a high specific capacitance of $1664.0 \mathrm{mF} \mathrm{cm}{ }^{-2}\left(27.0 \mathrm{~F} \mathrm{~cm}^{-3}\right)$ owing to the high yield of PPy/Ag nanoparticles with appropriate compactness and the synergistic effect of PPy, Ag and GO. The as-assembled QFSC based on the PPy $/ \mathrm{Ag} / 3 \mathrm{GO} / \mathrm{CF}_{120}$ electrode possesses maximum specific capacitance of $286.6 \mathrm{mF} \mathrm{cm} \mathrm{c}^{-2}(4.7 \mathrm{~F}$ $\mathrm{cm}^{-3}$ ), energy density of $25.5 \mu \mathrm{Wh} \mathrm{cm} \mathrm{cm}^{-2}$ and power density of $1149.5 \mu \mathrm{W} \mathrm{cm}{ }^{-2}$. In addition, the device retains $89.7 \%$ of its original capacitance after 10000 bending cycles, exhibiting its excellent mechanical flexibility and electrochemical stability. In light of the outstanding electrochemical performance and feasible preparation process, this study offers an effective method to obtain flexible and wearable energy storage device high-performance.

\section{Declarations}

\section{ACKNOWLEDGMENT}

We acknowledge support from the National Natural Science Foundation of China (No. 51763008), the Natural Science Foundation of Guangxi Province (No. 2019GXNSFAA245028, 2018GXNSFAA281241), and the Opening Project of Guangxi Key Laboratory of Calcium Carbonate Resources Comprehensive Utilization (HZXYKFKT201909).

\section{References}

1. Ardizzone S, Fregonara G, Trasatti S (1990) Inner and outer active surface of $\mathrm{RuO}_{2}$ electrodes. Electrochim Acta 35:263-267. https://doi.org/10.1016/0013-4686(90)85068-x

2. Barakzehi M, Montazer M, Sharif F, Norby T, Chatzitakis A (2019) A textile-based wearable supercapacitor using reduced graphene oxide/polypyrrole composite. Electrochim Acta 305:87-196. https://doi.org/10.1016/j.electacta.2019.03.058

3. Cai Y, Wu D, Zhu X, Wang W, Tan F, Chen J, Qiao X, Qiu X (2017) Sol-gel preparation of Ag-doped MgO nanoparticles with high efficiency for bacterial inactivation. Ceram Int 43:1066-1072. https://doi.org/10.1016/j.ceramint.2016.10.041

4. Cao J, Wang Y, Chen J, Li X, Walsh FC, Ouyang JH, Jia D, Zhou Y (2015) Three-dimensional graphene oxide/polypyrrole composite electrodes fabricated by one-step electrodeposition for high 
performance supercapacitors. J Mater Chem A 3:14445-14457.

https://doi.org/10.1039/C5TA02920A

5. Dubal DP, Chodankar NR, Kim DH, Gomez-Romero P (2018) Towards flexible solid-state supercapacitors for smart and wearable electronics. Chem Soc Rev 47:2065-2129. https://doi.org/10.1039/C7CS00505A

6. Fan Z, Zhu J, Sun X, Cheng Z, Liu Y, Wang Y (2017) High density of free-standing holey graphene/PPy films for superior volumetric capacitance of supercapacitors. ACS Appl Mater Interfaces 9:21763-21772. https://doi.org/10.1021/acsami.7b03477

7. Han Y, Zhang Z, Yang M, Li T, Wang Y, Cao A, Chen Z (2018) Facile preparation of reduced graphene oxide/polypyrrole nanocomposites with urchin-like microstructure for wide-potential-window supercapacitors. Electrochim Acta 289:238-247. https://doi.org/10.1016/j.electacta.2018.09.040

8. Hao B, Deng Z, Bi S, Ran J, Cheng D, Luo L, Cai G, Wang X, Tang X (2021) In situ polymerization of pyrrole on CNT/cotton multifunctional composite yarn for supercapacitors. Ionics 27:279-288. https://doi.org/10.1007/s11581-020-03784-2

9. Huang L, Santiago D, Loyselle P, Dai L (2018) Graphene-based nanomaterials for flexible and wearable supercapacitors. Small 14:1800879. https://doi.org/10.1002/smll.201800879

10. Jia R, Shen G, Qu F, Chen D (2020) Flexible on-chip micro-supercapacitors: Efficient power units for wearable electronics. Energy Storage Mater 27:169-186.

https://doi.org/10.1016/j.ensm.2020.01.030

11. Keum K, Kim JW, Hong SY, Son JG, Lee SS, Ha JS (2020) Flexible/stretchable supercapacitors with novel functionality for wearable electronics. Adv Mater 32:2002180.

https://doi.org/10.1002/adma.202002180

12. Kim YK, Shin KY (2021) Dopamine-assisted chemical vapour deposition of polypyrrole on graphene for flexible supercapacitor. Appl Surf Sci 547:149141. https://doi.org/10.1016/j.apsusc.2021.149141

13. Li J, Sun Y, Wang J, Tian J, Zhang X, Yang H, Lin B (2018) Synthesis, structure and electrochemical properties of novel ternary composite reduced-graphene oxide/ $\mathrm{Ag}$ nanoparticles/poly(pphenylenediamine). J Alloys Compd 749:783-793. https://doi.org/10.1016/j.jallcom.2018.03.326

14. Li Z, Huang T, Gao W, Xu Z, Chang D, Zhang C, Gao C (2017) Hydrothermally activated graphene fiber fabrics for textile electrodes of supercapacitors. ACS Nano 11:11056-11065. https://doi.org/10.1021/acsnano.7b05092

15. Li Z, Li M, Fan Q, Qi X, Qu L, Tian MW (2021) Smart-fabric-based supercapacitor with long-term durability and waterproof properties toward wearable applications. ACS Appl Mater Interfaces 13:14778-14785. https://doi.org/10.1021/acsami.1c02615

16. Li Z, Tian M, Sun X, Zhao H, Zhu S, Zhang X (2019) Flexible all-solid planar fibrous cellulose nonwoven fabric-based supercapacitor via capillarity-assisted graphene/ $\mathrm{MnO}_{2}$ assembly. $\mathrm{J}$ Alloy Compd 782:986-994. https://doi.org/10.1016/j.jallcom.2018.12.254 
17. Liang C, Yang C, Zang L, Liu Q, Qiu J, Li Y, Zuo W, Liu X (2021) UV-assisted one-step synthesis of ternary graphene/polypyrrole/silver nanocomposites for supercapacitors. Energy Technol 9:2000966. https://doi.org/10.1002/ente.202000966

18. Liu K, Yao Y, Lv T, Li H, Li N, Chen Z, Qian G, Chen T (2020b) Textile-like electrodes of seamless graphene/nanotubes for wearable and stretchable supercapacitors. J Power Sources 446:227355. https://doi.org/10.1016/j.jpowsour.2019.227355

19. Liu Q, Qiu J, Yang C, Zang L, Zhang G, Sakai E (2020a) High-performance textile electrode enhanced by surface modifications of fiberglass cloth with polypyrrole tentacles for flexible supercapacitors. Int J Energy Res 44:9166-9176. https://doi.org/10.1002/er.5558

20. Liu Q, Zang L, Qiao X, Qiu J, Wang X, Hu L, Yang J, Yang C (2019) Compressible all-in-one supercapacitor with adjustable output voltage based on polypyrrole-coated melamine foam. Adv Electron Mater 5:1900724. https://doi.org/10.1002/aelm.201900724

21. Lv J, Zhang L, Zhong Y, Sui X, Wang B, Chen Z, Feng X, Xu H, Mao Z (2019a) High-performance polypyrrole coated knitted cotton fabric electrodes for wearable energy storage. Org Electron 74:5968. https://doi.org/10.1016/j.orgel.2019.06.027

22. Lv J, Zhou P, Zhang L, Zhong Y, Sui X, Wang B, Chen Z, Xu H, Mao Z (2019b) High-performance textile electrodes for wearable electronics obtained by an improved in situ polymerization method. Chem Eng J 361:897-907. https://doi.org/10.1016/j.cej.2018.12.083

23. Purkait T, Singh G, Kumar D, Singh M, Ramendra Sundar Dey RS (2018) High-performance flexible supercapacitors based on electrochemically tailored three-dimensional reduced graphene oxide networks. Sci Rep 8:1-13. https://doi.org/10.1038/s41598-017-18593-3

24. Saleem H, Haneef M, Abbasi HY (2018) Synthesis route of reduced graphene oxide via thermal reduction of chemically exfoliated graphene oxide. Mater Chem Phys 204:1-7. https://doi.org/10.1016/j.matchemphys.2017.10.020

25. Singu BS, Yoon KR (2018) Highly exfoliated GO-PPy-Ag ternary nanocomposite for electrochemical supercapacitor. Electrochim Acta 268:304-315. https://doi.org/10.1016/j.electacta.2018.02.076

26. Sumboja A, Liu J, Zheng WG, Zong Y, Zhang H, Liu Z (2018) Electrochemical energy storage devices for wearable technology: A rationale for materials selection and cell design. Chem Soc Rev 47:59195945. https://doi.org/10.1039/C8CS00237A

27. Tian J, Wu S, Yin X, Wu W (2019) Novel preparation of hydrophilic graphene/graphene oxide nanosheets for supercapacitor electrode. Appl Surf Sci 496:143696. https://doi.org/10.1016/j.apsusc.2019.143696

28. Wang B, Li Z, Yin Y, Wang C (2021) Center and multi-points current collecting for improving capacitances of rectangular polypyrrole/knitted cotton fabric-based supercapacitor. J Power Sources 481:228824. https://doi.org/10.1016/j.jpowsour.2020.228824

29. Wang N, Han G, Xiao Y, Li Y, Song H, Zhang Y (2018a) Polypyrrole/graphene oxide deposited on two metalized surfaces of porous polypropylene films as all-in-one flexible supercapacitors. Electrochim Acta 270:490-500. https:// doi.org/10.1016/j.electacta.2018.03.090 
30. Wang N, Wang X, Zhang Y, Hou W, Chang Y, Song H, Zhao Y, Han G (2020b) All-in-one flexible asymmetric supercapacitor based on composite of polypyrrole-graphene oxide and poly(3,4ethylenedioxythiophene). J Alloy Compd 835:155299.

https://doi.org/10.1016/j.jallcom.2020.155299

31. Wang W, Sadak O, Guan J, Gunasekaran S (2020a) Facile synthesis of graphene paper/polypyrrole nanocomposite as electrode for flexible solid-state supercapacitor. J Energy Storage 30:101533. https://doi.org/10.1016/j.est.2020.101533

32. Wang Y, Zhang Y, Zhong W, Qing X, Zhou Q, Liu Q, Wang W, Liu X, Li M, Wang D (2018b) Flexible supercapacitor with high energy density prepared by GO-induced porous coral-like polypyrrole (PPy)/PET non-woven fabrics. J Mater Sci 53:8409-8419. https://doi.org/10.1007/s10853-0182131-9

33. Wei J, Xing G, Gao L, Suo H, He X, Zhao C, Li S, Xing S (2013) Nickel foam based polypyrrole-Ag composite film: a new route toward stable electrodes for supercapacitors. New J Chem 37:337-341. https://doi.org/10.1039/C2NJ40590C

34. Wu DY, Shao JJ (2021) Graphene-based flexible all-solid-state supercapacitors. Mater Chem Front 5:557-583. https://doi.org/10.1039/d0qm00291g

35. Xu L, Shi R, Li H, Han C, Wu M, Wong CP, Kang F, Li B (2018) Pseudocapacitive anthraquinone modified with reduced graphene oxide for flexible symmetric all-solid-state supercapacitors. Carbon 127:459-468. https://doi.org/10.1016/j.carbon.2017.11.003

36. Yang C, Hu L, Zang L, Liu Q, Qiu J, Yang J, Qiao X (2020) High-performance all-solid-state supercapacitor based on activated carbon coated fiberglass cloth using asphalt as active binder. $J$ Electrochem Soc 167:020540. https://doi.org/10.1149/1945-7111/ab6bbb

37. Yu P, Zeng Y, Zhang H, Yu M, Tong Y, Lu X (2019) Flexible Zn-ion batteries: Recent progresses and challenges. Small 15:1804760. https://doi.org/10.1002/smll.201804760

38. Zang L, Liu Q, Qiu J, Yang C, Wei C, Liu C, Lao L (2017) Design and fabrication of an all-solid-state polymer supercapacitor with highly mechanical flexibility based on polypyrrole hydrogel. ACS Appl Mater Interfaces 9:33941-33947. https://doi.org/10.1021/acsami.7b10321

39. Zang L, Qiao X, Liu Q, Yang C, Hu L, Yang J, Ma Z (2020) High-performance solid-state supercapacitors with designable patterns based on used newspaper. Cellulose 27:1033-1042. https://doi.org/10.1007/s10570-019-02856-5

40. Zang L, Qiu J, Yang C, Sakai E (2016) Preparation and application of conducting polymer/Ag/clay composite nanoparticles formed by in situ UV-induced dispersion polymerization. Sci Rep 6:20470. https://doi.org/10.1038/srep20470

41. Zhang C, Tian J, Rao W, Guo B, Fan L, Xu W, Xu J (2019) Polypyrrole@metal-organic framework (UIO66)@cotton fabric electrodes for flexible supercapacitors. Cellulose 26:3387-3399. https://doi.org/10.1007/s10570-019-02321-3

42. Zhang X, Jiang C, Liang J, Wu W (2021) Electrode materials and device architecture strategies for flexible supercapacitors in wearable energy storage. J Mater Chem A 9:8099-8128. 
https://doi.org/10.1039/D0TA12299H

43. Zhang X, Wang J, Liu J, Wu J, Chen H, Bi H (2017) Design and preparation of a ternary composite of graphene oxide/carbon dots/polypyrrole for supercapacitor application: Importance and unique role of carbon dots. Carbon 115:134-146. https://doi.org/10.1016/j.carbon.2017.01.005

44. Zhou C, Wang Q, Yan XH, Wang JJ, Wang DF, Yuan XX, Jiang H, Zhu YH, Cheng XN (2020) A facile route to synthesize $\mathrm{Ag}$ decorated $\mathrm{MoO}_{3}$ nanocomposite for symmetric supercapacitor. Ceram Int 46:15385-15391. https://doi.org/10.1016/j.ceramint.2020.03.083

45. Zuo W, Zang L, Wang X, Liu Q, Qiu J, Liang C, Liu X, Yang C (2020) Flexible polypyrrole@ $\mathrm{Fe}_{2} \mathrm{O}_{3} @$ stainless steel yarn composite electrode for symmetric thread-like supercapacitor with extended operating voltage window in $\mathrm{Li}_{2} \mathrm{SO}_{4}$-based aqueous electrolyte. Adv Sustain Syst 4:2000173. https://doi.org/10.1002/adsu.202000173

\section{Figures}

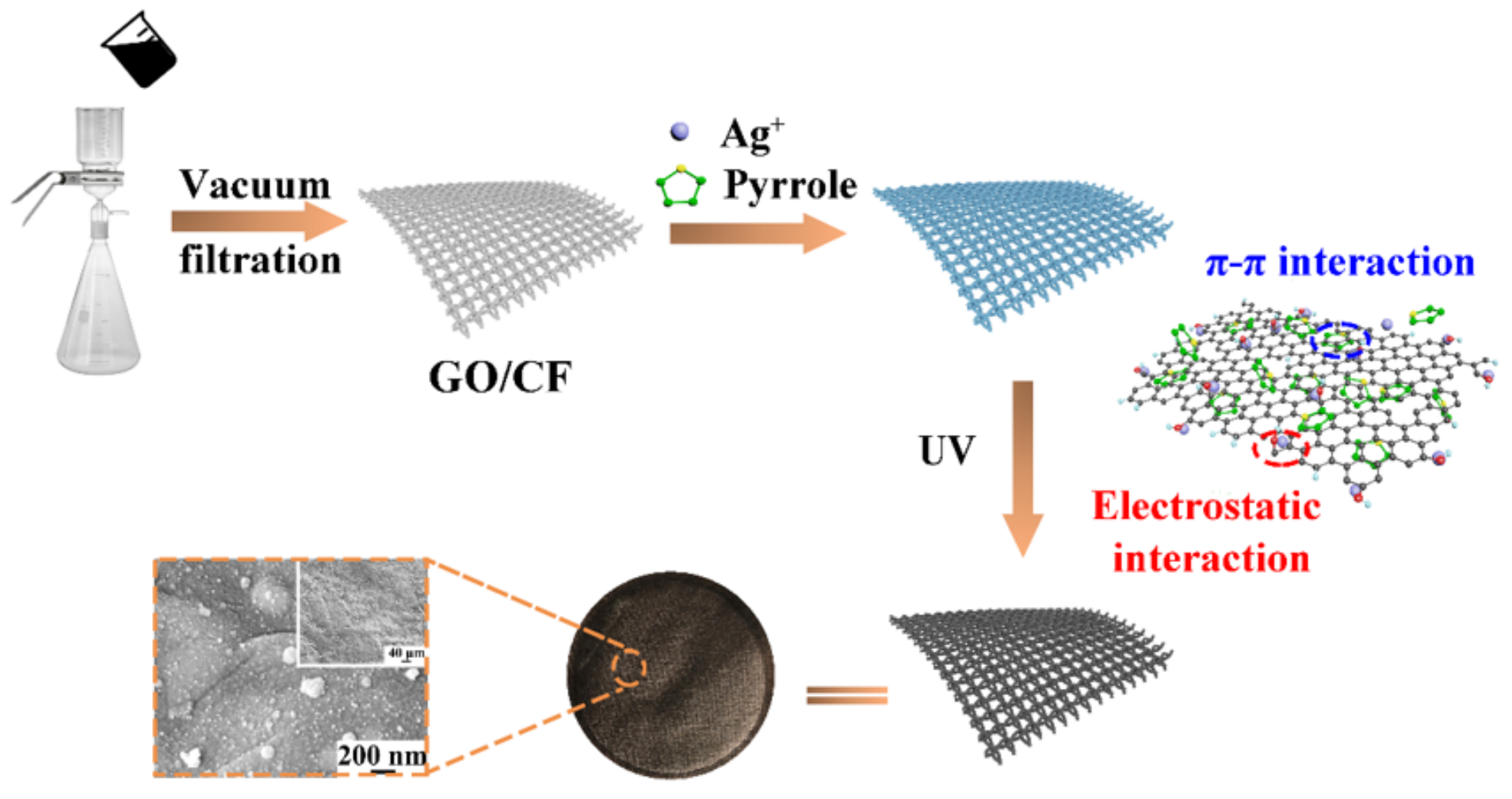

\section{PPy/Ag/GO/CF}

\section{Figure 1}

Schematic fabrication process of the flexible PPy/Ag/GO/CF electrodes 

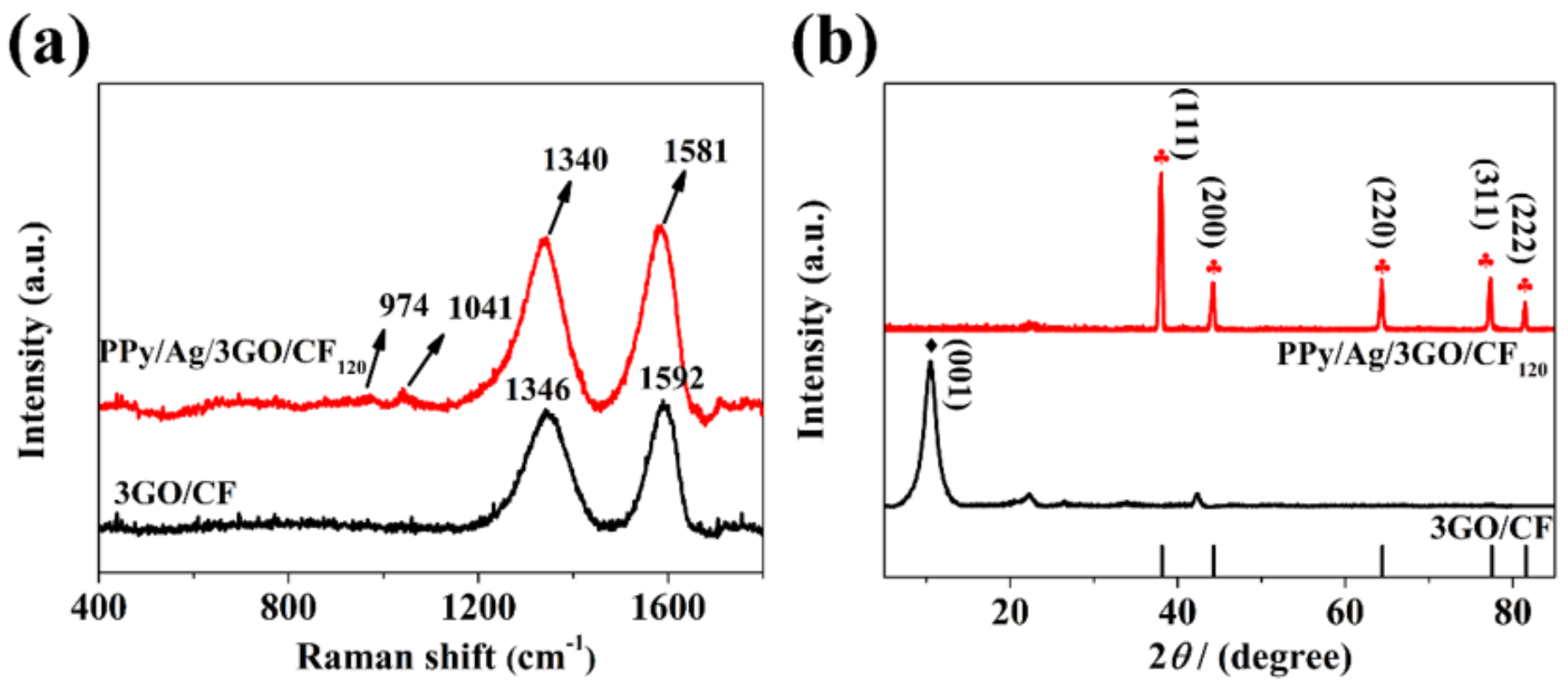

Figure 2

a Raman spectra and b XRD patterns of 3GO/CF and PPy/Ag/3GO/CF120 
(a)
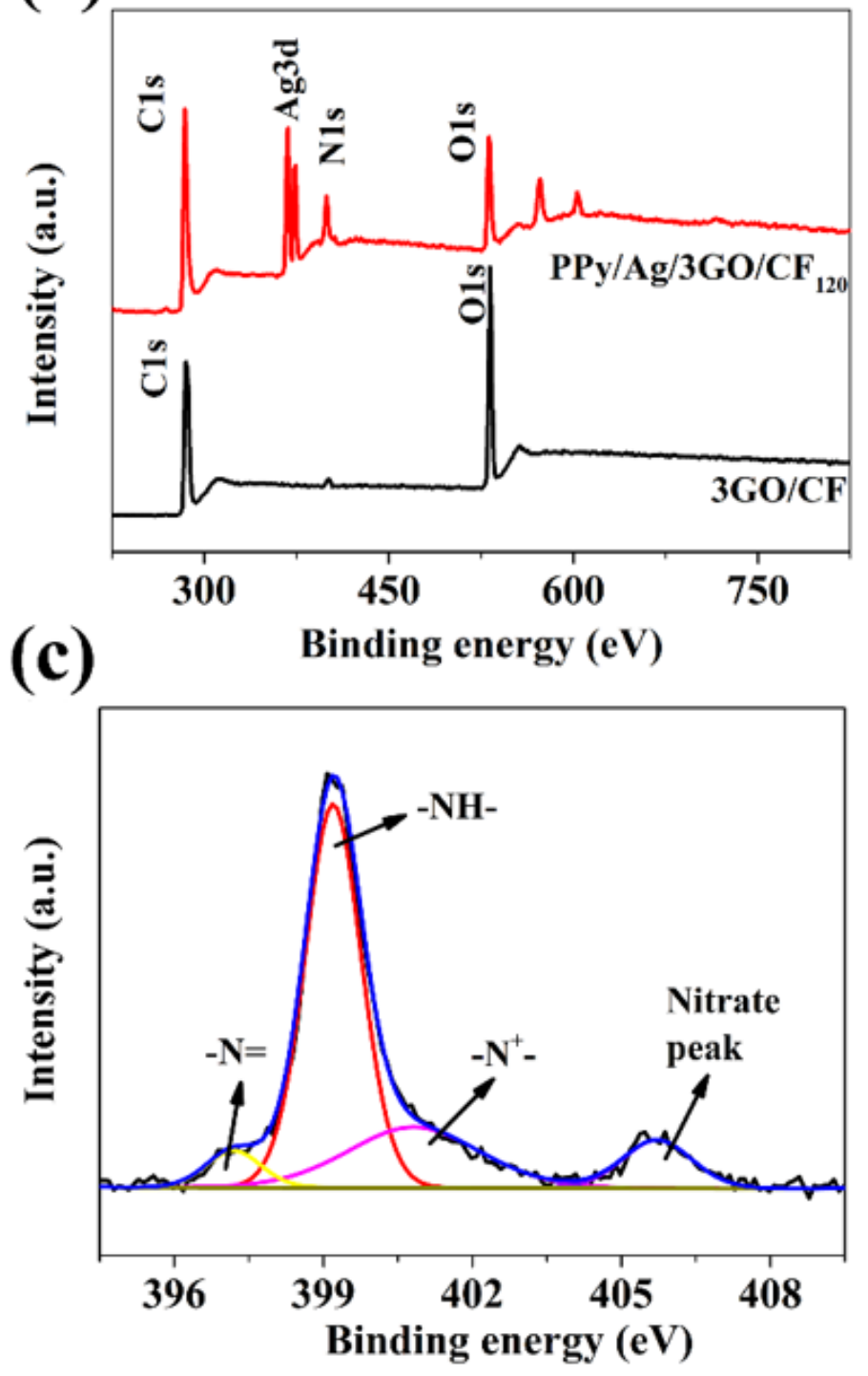

(b)
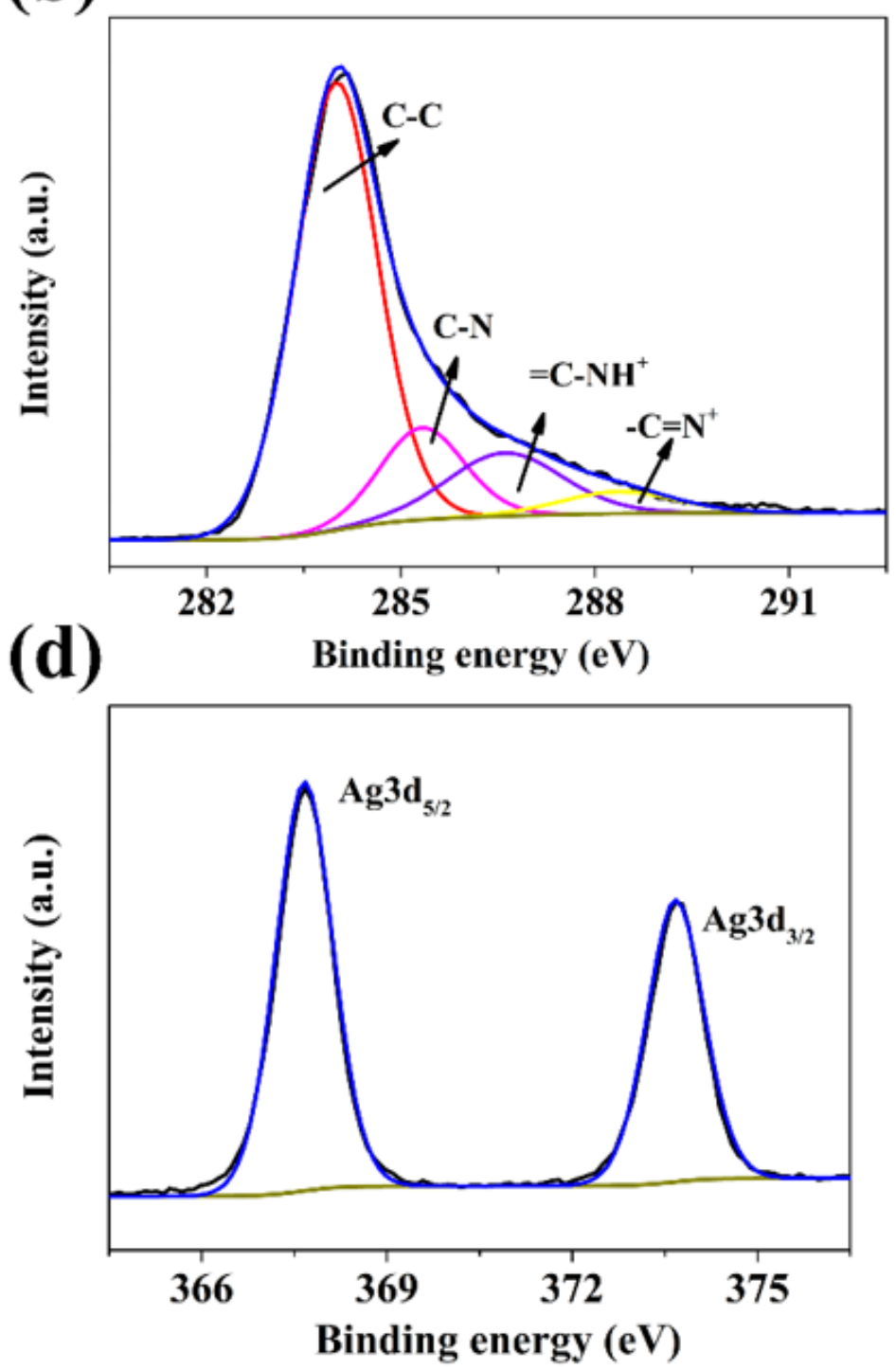

Figure 3

a XPS survey spectra of $3 \mathrm{GO} / \mathrm{CF}$ and PPy/Ag/3GO/CF120 and corresponding XPS spectra of b C1s, c $\mathrm{N} 1 \mathrm{~s}$ and $\mathrm{d} \mathrm{Ag} 3 \mathrm{~d}$ in the PPy/Ag/3GO/CF120 


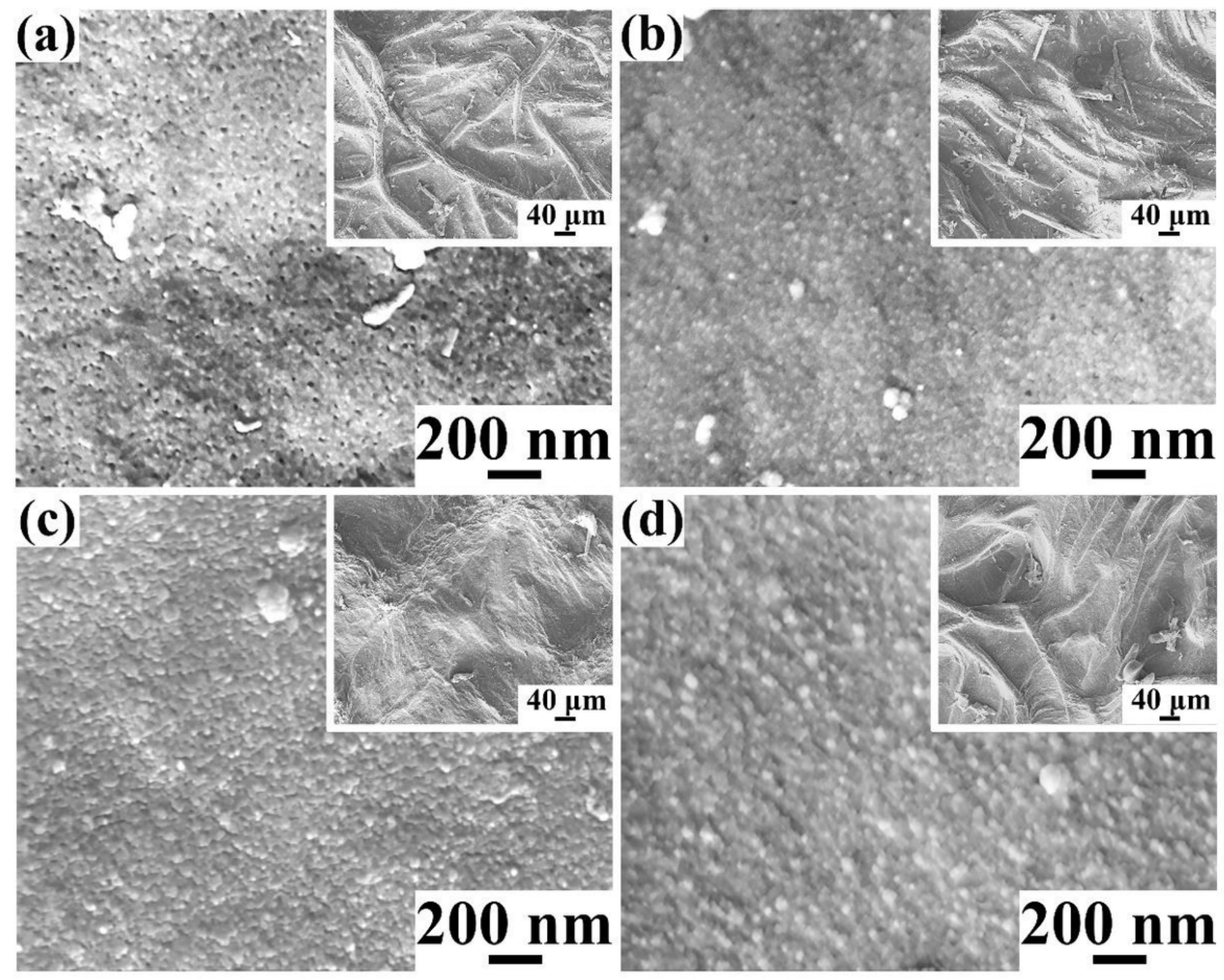

Figure 4

SEM images of a PPy/Ag/1GO/CF60, b PPy/Ag/1GO/CF90, c PPy/Ag/1GO/CF120 and d $\mathrm{PPy} / \mathrm{Ag} / 1 \mathrm{GO} / \mathrm{CF} 150$

(a)

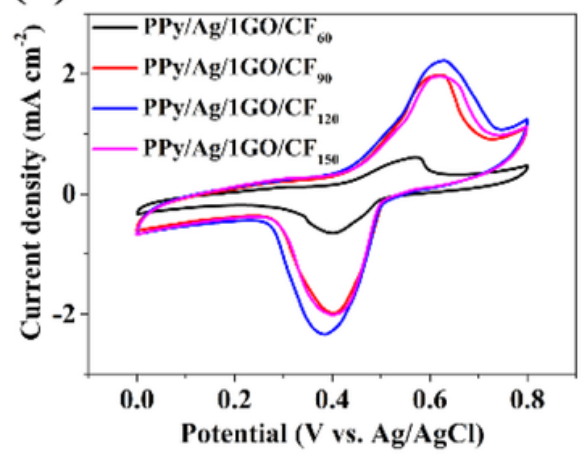

(b)

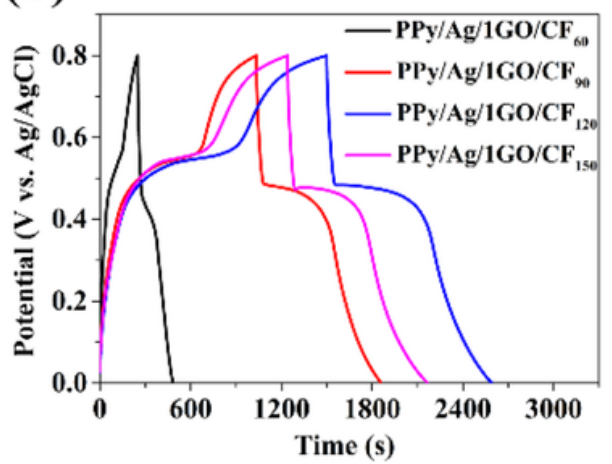

(c)

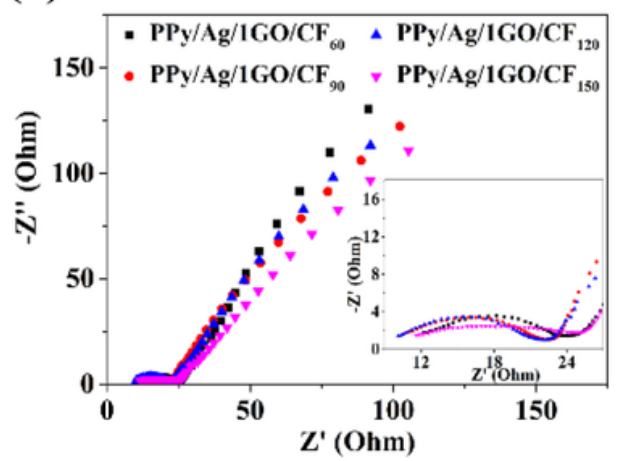

Figure 5 
Electrochemical properties of PPy/Ag/1GO/CFy electrodes. a CV curves at $1 \mathrm{mV} \mathrm{s}-1 ; \mathrm{b}$ GCD curves at 0.5 $\mathrm{mA} \mathrm{cm}-2$; c Nyquist plots

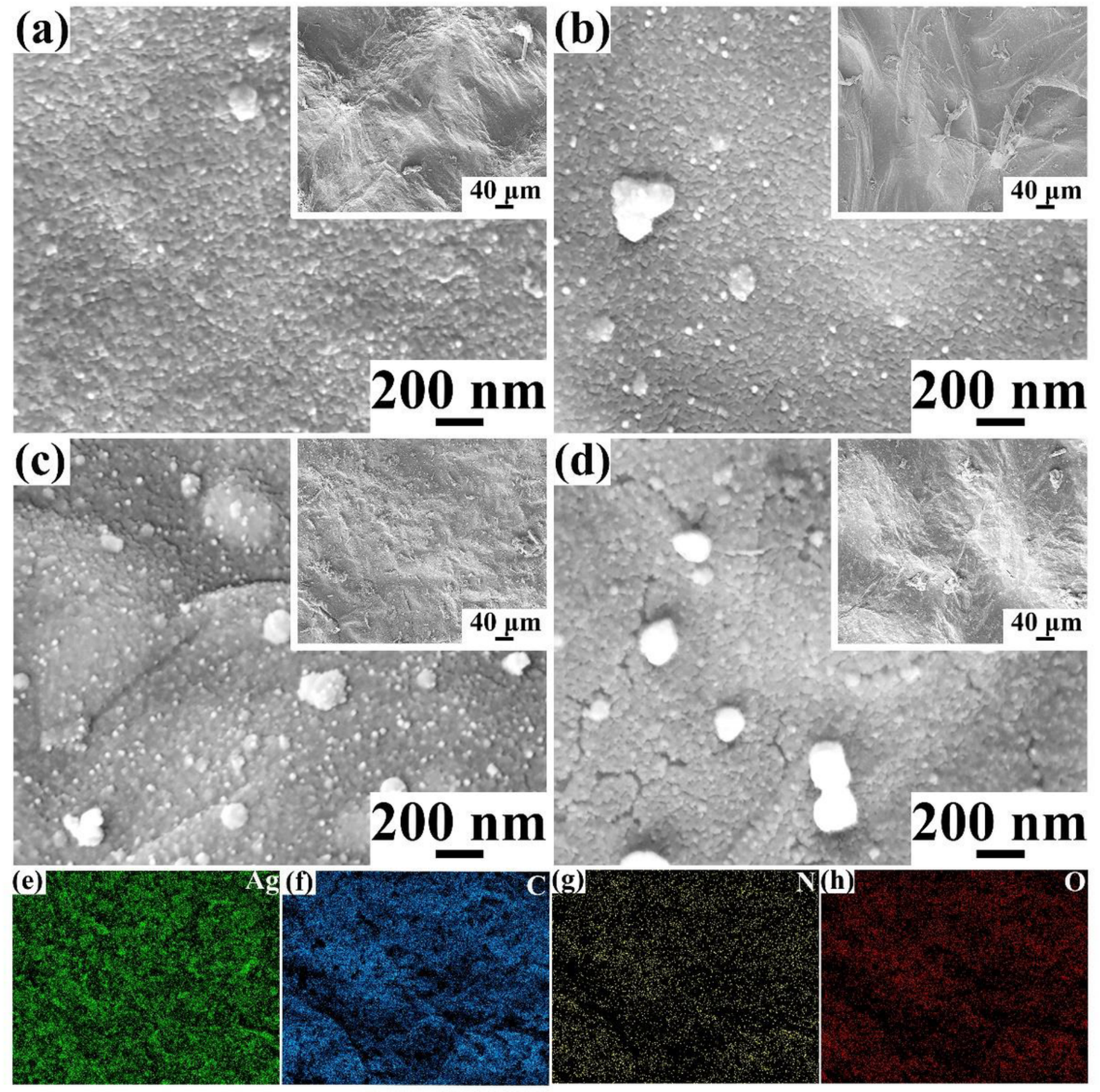

Figure 6

SEM images of a PPy/Ag/1GO/CF120, b PPy/Ag/2GO/CF120, c PPy/Ag/3GO/CF120 and d $\mathrm{PPy} / \mathrm{Ag} / 4 \mathrm{GO} / \mathrm{CF} 120$; EDS mappings of e $\mathrm{Ag}, \mathrm{f} \mathrm{C,} \mathrm{g} \mathrm{N}$ and $\mathrm{h} \mathrm{O}$ of PPy/Ag/3GO/CF120 
(a)

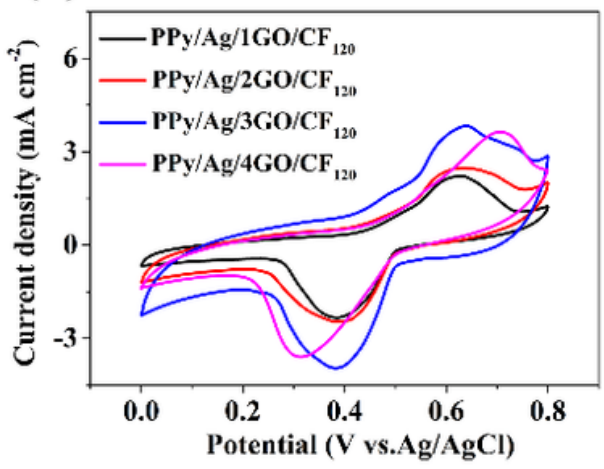

(b)

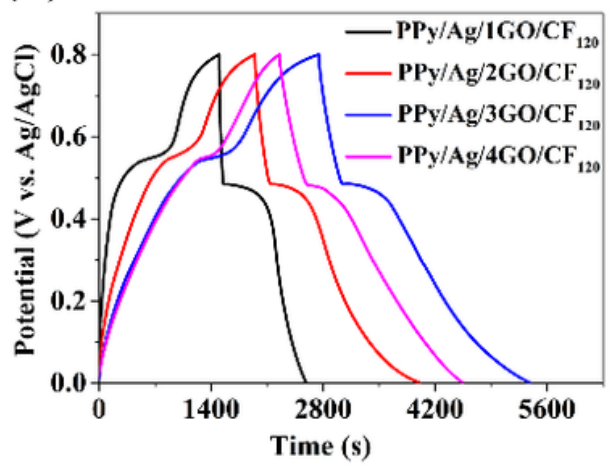

(c)

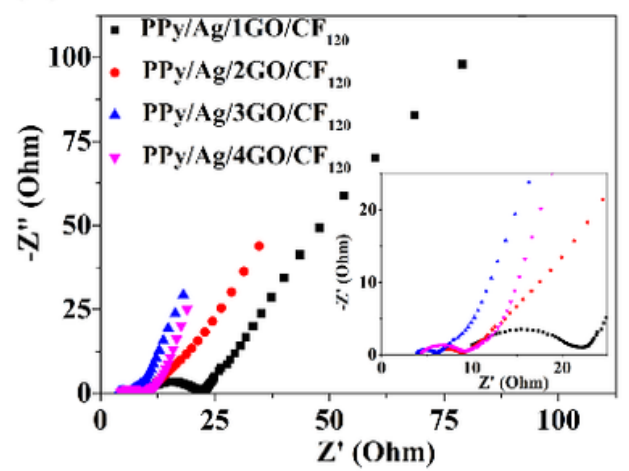

Figure 7

Electrochemical properties of PPy/Ag/xGO/CF120 electrodes. a CV curves at $1 \mathrm{mV} \mathrm{s}-1 ; \mathrm{b}$ GCD curves at $0.5 \mathrm{~mA} \mathrm{~cm}-2$; c Nyquist plots

(a)

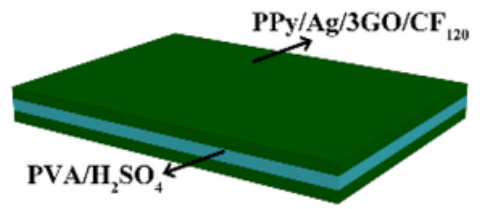

(d)

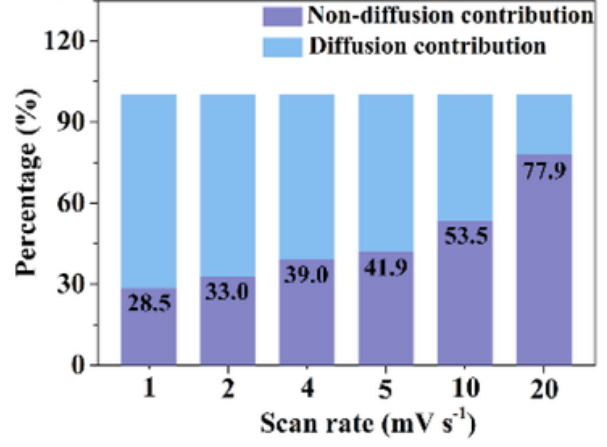

(b)

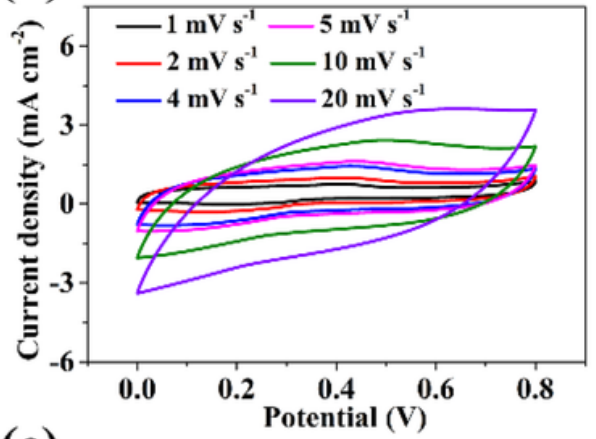

(e)

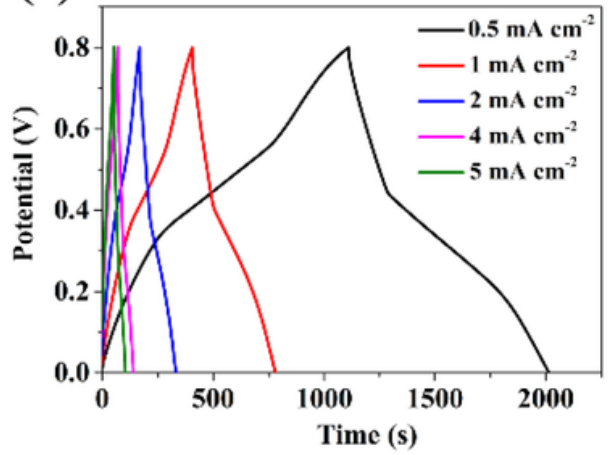

(c)

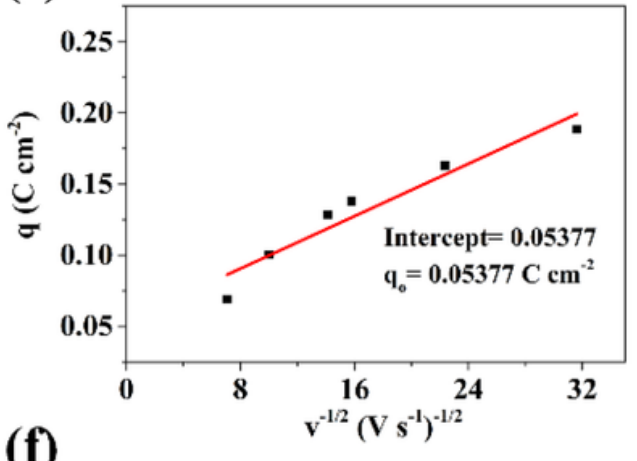

(f)

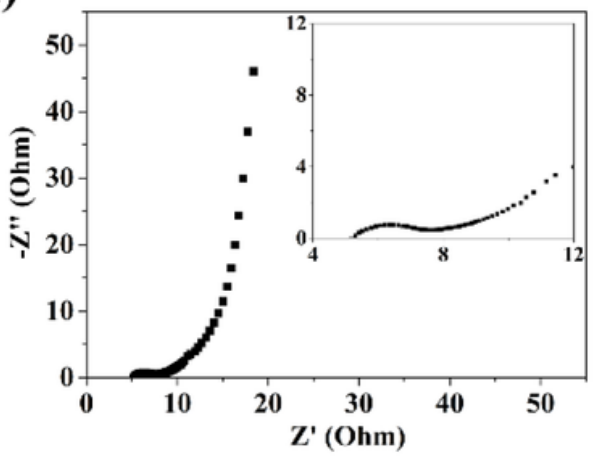

Figure 8

Electrochemical properties of the QFSC based on the PPy/Ag/3GO/CF120 electrode. a Structure schematic illustration; $b$ CV curves at different scan rates; $c$ The dependence of q_v on $v^{\wedge}((-1) / 2)$; $d$ The ratios of non-diffusion contribution at different scan rates; e GCD curves at various current densities; $f$ Nyquist plots 
(a)

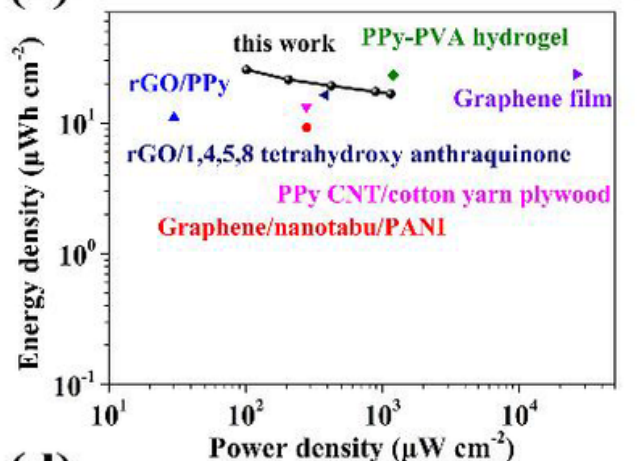

(d)

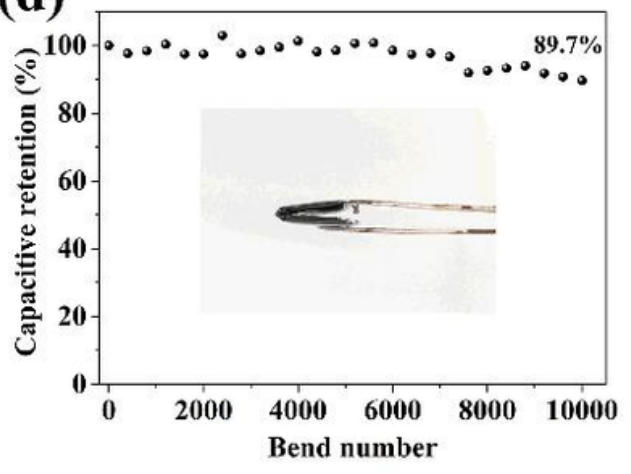

(b)

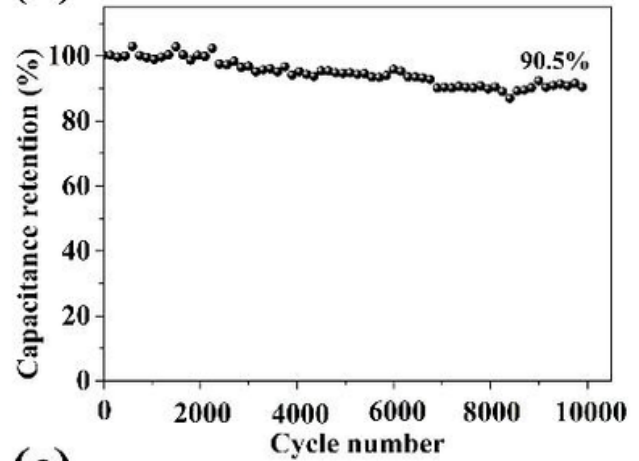

(e)

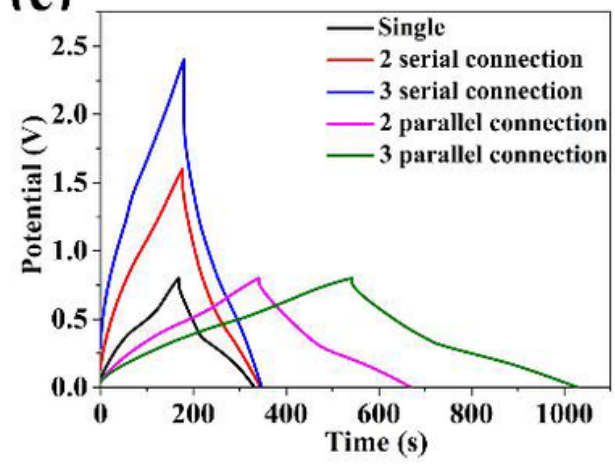

(c)

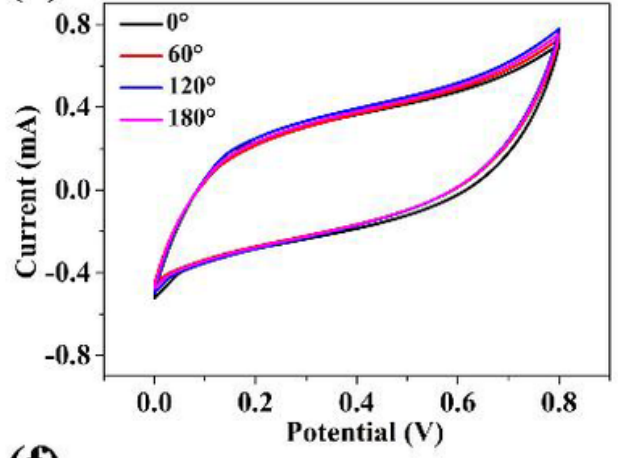

(f)

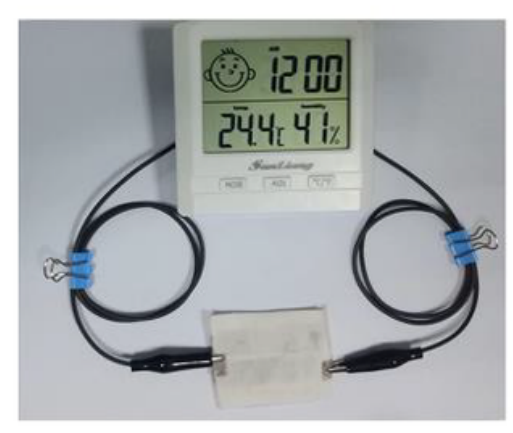

Figure 9

Electrochemical performance of the QFSC based on the PPy/Ag/3GO/CF120 electrode. a Ragone plots; $b$ Cycling stability at $8 \mathrm{~mA} \mathrm{~cm}-2$; c CV curves at $10 \mathrm{mV} \mathrm{s}-1$ under different bending angles; $\mathrm{d}$ Capacitance retention during 10000 bending cycles at a bending angle of $180^{\circ}$; e GCD curves of QFSCs connected in series and in parallel; $f$ Digital image of an electronic clock powered by three QFSCs connected in series.

\section{Supplementary Files}

This is a list of supplementary files associated with this preprint. Click to download.

- SupportingInformation.docx 